Article

\title{
Sustainable Supply of Safe Drinking Water for Underserved Households in Kenya: Investigating the Viability of Decentralized Solutions
}

\section{Pauline Chepchirchir Cherunya ${ }^{1}$, Christine Janezic ${ }^{2}$ and Michael Leuchner ${ }^{1,3, *}$}

1 Technische Universität München, Hans-Carl-von-Carlowitz-Platz 2, Freising 85354, Germany; E-Mail: leuchner@wzw.tum.de

2 Siemens Stiftung, Kaiserstr. 16, Munich 80801, Germany;

E-Mail: christine.janezic@siemens-stiftung.org

3 Institute for Advanced Study, Technische Universität München, Lichtenbergstraße 2a, Garching D-85748, Germany

* Author to whom correspondence should be addressed; E-Mail: leuchner@wzw.tum.de; Tel.: +49-8161-714-745; Fax: +49-8161-714-753.

Academic Editor: David Kreamer

Received: 8 July 2015 / Accepted: 8 October 2015 / Published: 14 October 2015

\begin{abstract}
Water quality and safe water sources are pivotal aspects of consideration for domestic water. Focusing on underserved households in Kenya, this study compared user perceptions and preferences on water-service provision options, particularly investigating the viability of decentralized models, such as the Safe Water Enterprise (SWE), as sustainable safe drinking water sources. Results showed that among a number of water-service provision options available, the majority of households regularly sourced their domestic water from more than one source (86\% Ngoliba/Maguguni, 98\% Kangemi Gichagi). A majority of households perceived their water sources to be unsafe to drink (84\% Ngoliba/Maguguni, 73\% Kangemi Gichagi). For this reason, drinking water was mainly chlorinated (48\% Ngoliba/Maguguni, 33\% Kangemi Gichagi) or boiled (42\% Ngoliba/Maguguni, 67\% Kangemi Gichagi). However, this study also found that households in Kenya did not apply these household water treatment methods consistently, thus indicating inconsistency in safe water consumption. The SWE concept, a community-scale decentralized safe drinking water source, was a preferred option among households who perceived it to save time and to be less cumbersome as compared to boiling and chlorination. Willingness to pay for SWE water was also a positive indicator for its
\end{abstract}


preference by the underserved households. However, the long-term applicability of such decentralized water provision models needs to be further investigated within the larger water-service provision context.

Keywords: consistency; decentralization; safe water; small-scale systems; Safe Water Enterprises (SWE)

\section{Introduction}

Water quality is a major aspect in the discussions on improvement of water-service provision. In many places in the world, the limits to the assimilative capacity of water resources has already been reached, due to human and industrial waste [1]. Volumes of water are therefore unsuitable for human consumption and further use. One of the biggest preventable health burdens in the world, water-borne diseases, is due to insufficient access to safe drinking water and inadequate sanitation. In fact, the lack of safe water, sanitation and hygiene is the cause of $88 \%$ of diarrheal disease cases worldwide, resulting in 1.5 million deaths each year [2]. The vast impact of unsafe water and lack of sanitation is underlined in several of the Millennium Development Goals (MDGs). In addition to the MDG target (Goal 7) of improving water access and providing adequate sanitation, safe drinking water is also closely linked to health and nutrition targets (Goals 1, 4, 5 and 6), environmental sustainability (Goal 7), gender equality (Goal 3), primary school attendance (Goal 2), and overall poverty rates (Goal 1) [3]. Creating adequate access to safe drinking water remains one of the primary ways of addressing the problem of water-borne diseases as well as the other challenges related to the MDGs. With volumes of water being rendered unsuitable for use worldwide, water treatment has come to the forefront of efforts for improved water-service provision.

\subsection{Background}

Low-income urban areas and the rural areas in developing countries are largely cut off from infrastructural services, leading to a lack of sustainable access to basic services. In these underserved areas, access to safe domestic water has been a major challenge. The coverage of improved water and sanitation has been found to strongly correlate to household income as well as dwelling location [3]. This indicates severe inequalities in water-service provision between the rich and the poor as well as between rural and urban populations [3,4]. In Kenya, only $12 \%$ of the rural population is served by formal piped household connections as compared to $86.4 \%$ in urban areas [5]. The inadequate coverage of water services in rural Kenya has been linked to the historical lack of financial and administrative capacities in the water sector [6]. Preference for centralized and networked system designs that are poorly applicable in rural areas where populations are scattered have also been attributed to the inadequate coverage of water services in rural Kenya [7,8]. In urban areas of Kenya, access to water services is highly unequal as well. The densely populated low-income urban areas, many of which are large unplanned informal settlements, remain underserved. There are a number of reasons leading to utility developers' abstention from investments in low-income urban areas: uncertainties regarding land ownership [9], the view that 
utilities development in low-income urban areas is commercially unattractive [10], or the perception that informal areas have infrastructural problems that are too difficult to be managed $[9,10]$. It is estimated that the coverage of formalized water supply services to informal settlements in Kenya are often as low as 20\% [11]. The Water Services Regulatory Board [5] stated that the inequality in urban water provision in Kenya has its roots in poor planning, presence of informal settlements, networked designs favoring high-end users, design demand structures and supply vs. demand management.

Decentralization of basic services has gained increasing attention in the last decades [12] as an approach that could solve the problem of lack of access to safe drinking water. Peter-Varbanets et al. [13] for instance argued that decentralized systems are often the only means to improve both water quality and quantity problems, especially where both are lacking. The concept of decentralization has gained popularity, especially in developing countries, in reaction to what is widely agreed to be the failure of highly-centralized governments to deliver basic services to their citizens [14]. In a broad sense, decentralization is accepted to denote the redistribution of power and responsibility to plan, make decisions and manage public functions among different levels of government [15-17]. The definition of the term "decentralization" can vary substantially in scale and scope [17-19]. This research specifically looks into the benefits of decentralization regarding the extension of the mandate for water-service provision to non-State actors. Extending distribution of functions to non-State actors would bring increased investments into water-service provision and concurrently the possibility to reach larger amounts of people with the necessary services [20]. A further perceived benefit is that this approach will lead to more incentives for creative, innovative and responsive programs through "local experimentation" [20]. In Kenya, adopting the decentralization approach was also necessitated by the need to find ways to regulate small-scale private service providers who had previously been deemed informal and illegal. This is despite the fact that a significant percentage of households depended on them for water-service provision [21]. With the recognition that many households would go unserved if these small-scale private service providers were not present, the State, through the Water Act 2002, created conducive policy environments for their regulation, thereby further creating an opportunity for expansion of service coverage [21]. Kenya's Water Act 2002 created a "delegated management model" that gives criteria for private small-scale providers to be formally recognized, thereby enabling a regulation of their services. Kariuki and Schwartz [21] emphasized that working formally with small-scale private service providers will enable the establishment of measures to improve their quality, efficiency and affordability. Research carried out in a low-income urban area in Ghana [22] found that informal water-service providers do crucially fill the supply gap left by the formal centralized water-service provision systems. The researchers emphasized the fact that small-scale services generate a functioning infrastructure that is sufficiently flexible to deal with the challenges of water provision systems in informal areas. This is opposed to the more stationary, rigid distribution technologies of conventional piped water systems. In the Ghana study, Peloso and Morinville argued the need for policy makers to recognize small-scale water providers [22].

As an outcome of decentralization in water-service provision, innovative small-scale systems for water treatment at community level are being promoted. The reduction of capital costs as a result of reduced grid connection infrastructure is an economic driver for these decentralized small-scale systems [12]. Small-scale systems also increase the potential for financial sustainability [23]. Other benefits of decentralized small-scale systems have been discussed to result from the fact that they 
can be demand-driven and flexible according to local conditions [12]. Important success factors for decentralized small-scale systems have been defined to include low costs, ease of use, low maintenance and independence from utilities such as energy $[13,24]$. The Safe Water Enterprise (SWE) is an example of innovative small-scale systems for water treatment and safe water provision at the community level, applying to its concept the success factors for decentralized small-scale systems.

Developed by the charitable foundations Siemens Stiftung and the SkyJuice Foundation, the SWE presents a model for drinking water provision for underserved urban areas and rural areas in developing countries [25]. The SWE is an end-of-pipe water treatment system that delivers safe water to the consumer. The only task remaining for the household is the management of safe storage. The concept combines a low-cost and low-maintenance membrane-based water treatment technology with an entrepreneurial approach for the sustainable management of the utility. The operational model of the SWE foresees that sufficient revenues are collected to cover operational costs while still at the same time providing water at affordable costs to the low-income households [25]. As a solution to the challenges faced by the popular community-based management model, SWE utilities are placed in the ownership of community organizations, whereas the daily management of the utility is carried out by entrepreneurs on behalf of the community (Figure 1). The SWE supports moving away from voluntary arrangements towards more professional water-service provision in communities.

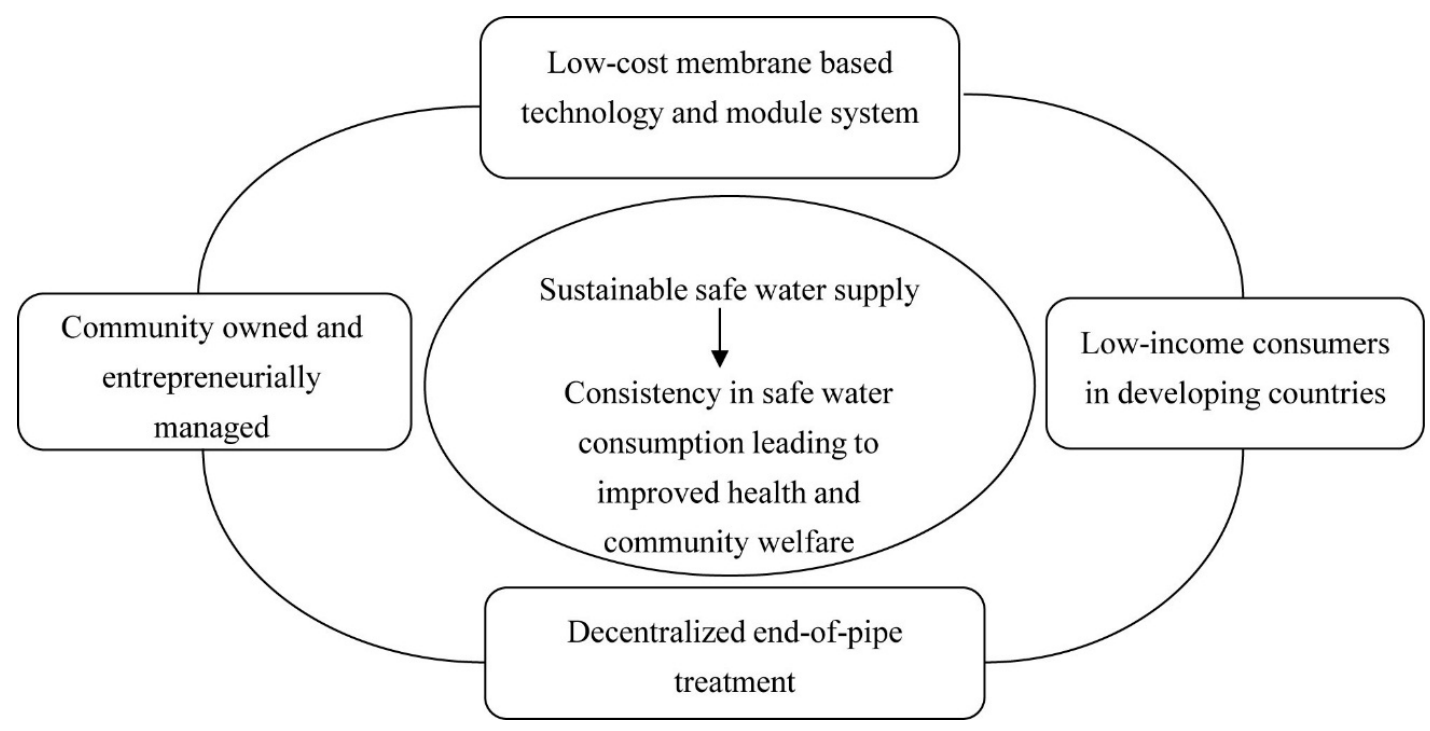

Figure 1. Description of the Safe Water Enterprise concept (edited after Sima and Elimelech [26]).

The SWE treats water from available surface or ground water sources that would otherwise have been consumed without prior treatment. The water is made safe for drinking through end-of-pipe treatment at a water kiosk, after which it can be collected by the consumers. In order to avoid recontamination of water, the SWE kiosk operator cleans and disinfects the clients' water containers. The water treatment technology used by the SWEs is a gravity-driven, ultrafiltration membrane technology, the SkyHydrant ${ }^{\mathbb{R}}$ (Sydney, Australia), which was developed and is produced by the charitable foundation SkyJuice Foundation. The SkyHydrant ${ }^{\circledR}$ purifies surface or ground water by removing all pathogens and turbidity [27]. The costs of membranes have decreased rapidly during the last decades and therefore membrane systems have become affordable for use in low-cost applications in developing countries [13]. Peter-Varbanets et al. [13] have suggested that important success factors for decentralized water-supply 
systems include ease of use, low maintenance, low costs and independence of utilities such as energy. The SkyHydrant ${ }^{\circledR}$ fulfills these criteria as it is easy to operate. The daily maintenance task for the kiosk operator is to perform a simple backwash, which requires very basic technical expertise [27]. The SkyHydrant ${ }^{\circledR}$ also works without electricity, which is of relevance particularly for underserved areas that are characterized by a lack of sufficient electricity connectivity. The unit cost of a SkyHydrant ${ }^{\circledR}$ is of approximately USD 3000 [28]. Based on an output of 10 L per person per day and on a customer base of 1000 people that can be supplied by one SkyHydrant ${ }^{\circledR}$, the unit has been determined to have an installed cost of less than USD 0.50 per person, per annum [28]. The costs have been calculated and the SkyHydrant's efficiency has been estimated based on its minimum lifespan of seven years [27,28]. The SkyHydrant ${ }^{\circledR}$ has the capacity to treat $1000 \mathrm{~L}$ of water per hour. This makes the SWE model and its technology appropriate to function as a decentralized small-scale system. They are designed to supply water to cluster villages in rural areas and low-income urban areas.

\subsection{Research Objectives and Research Questions}

The main objective of this work was to find out if water treatment solutions that apply the decentralized approach are a viable solution to realize consistency in safe water consumption by households. The World Health Organization [29] pointed out that in order to effectively use safe water as a preventive health intervention, individuals must correctly and consistently use the methods that make water safe for drinking. User perspective is an important factor of consideration in water sourcing and water use dynamics. User preferences and consumer demands are often overlooked which can easily lead to the development of inappropriate technologies and services [30]. This research thus sought to understand the perceptions of underserved households towards different water sources by also taking into consideration further factors influencing households' preferred choices. User perceptions towards the commonly available water sources are compared to user perceptions of the newly introduced decentralized SWE model - in both rural and urban settings. The research thus seeks to understand which factors enable a consistency of both safe water supply and safe water consumption. The following three research questions were at the core of the study:

(i) Which water provision options are available for underserved rural and urban households?

(ii) Which safe water practices are applied by the rural and urban underserved households, and what is the perception towards them?

(iii) Is there a difference in perceptions and preferences between the rural and urban areas?

\section{Study Areas and Methodology}

\subsection{Description of Study Areas}

The case study areas in Kenya were Kangemi Gichagi sub-location, representing an urban study area and Ngoliba and Maguguni sub-locations, representing a rural study area (Figure 2). Kangemi Gichagi is located about $10 \mathrm{~km}$ from Nairobi's central business district and covers an area of $0.87 \mathrm{~km}^{2}$, with a population density of 22,243 people $/ \mathrm{km}^{2}$ (Table 1) [31]. The SWE in Kangemi Gichagi is located at coordinates $1^{\circ} 16^{\prime} 17.4^{\prime \prime} \mathrm{S} \mathrm{36} 44^{\circ} 36.4^{\prime \prime}$ E. Ngoliba and Maguguni sub-locations are located about $60 \mathrm{~km}$ from Nairobi's central business district and cover an area of $44.42 \mathrm{~km}^{2}$, with a population density of 
252 people $/ \mathrm{km}^{2}$ according to the 2009 census report (Table 1) [31]. This study combined data from Ngoliba sub-location and Maguguni sub-location, which were analyzed together to represent the rural case study, hereby referred to as Ngoliba/Maguguni. The two sub-locations are adjacent to each other and have similar demographic and social conditions. The SWEs in Ngoliba and Maguguni are located at

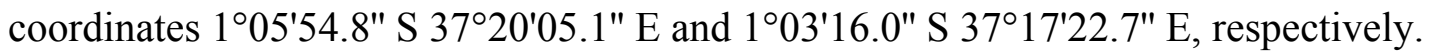

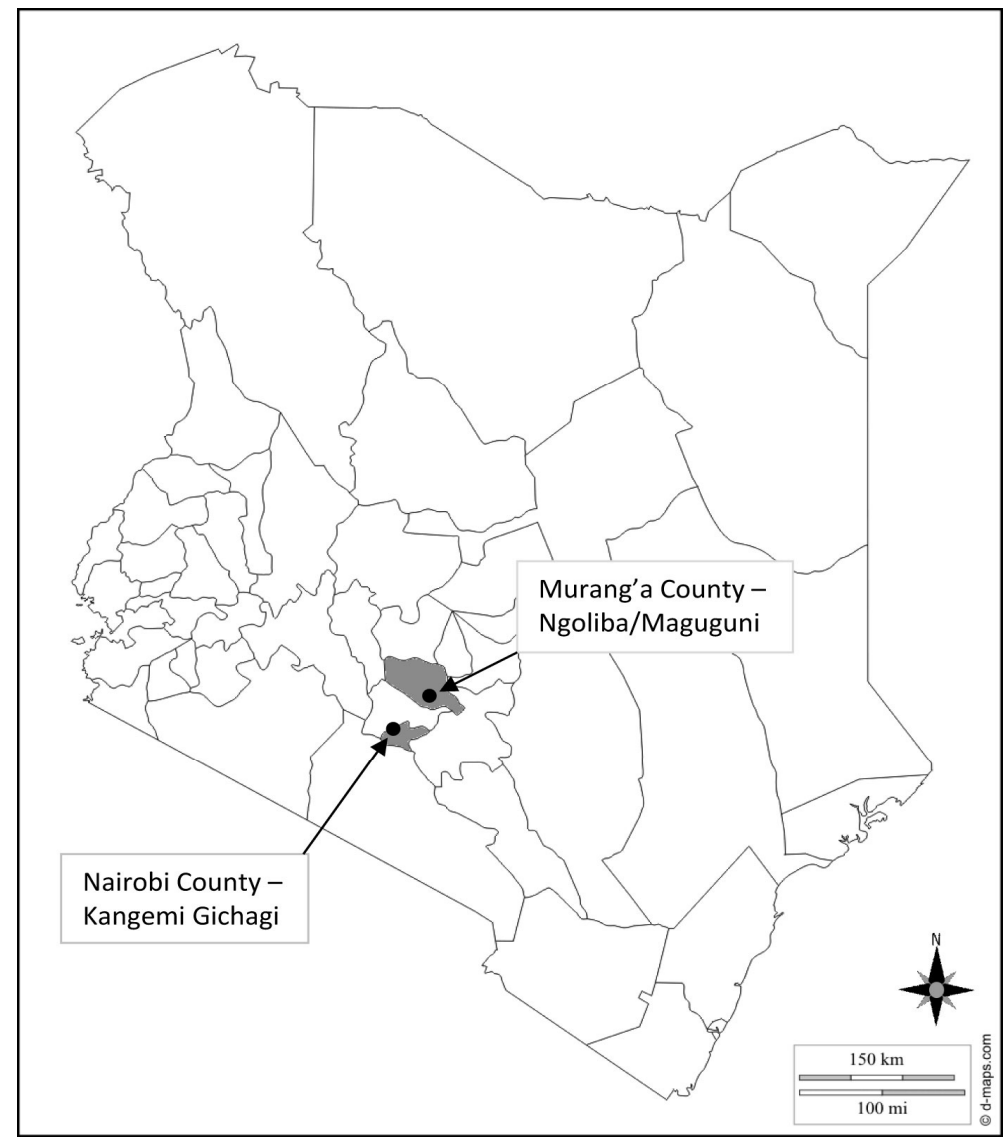

Figure 2. Administrative map of Kenya showing the study areas [32]. Due to changes in the administrative jurisdiction in Kenya, this research applied latest data from the 2009 Census, which is given as sub-locations. As of 2010, counties were constituted, of which representative maps could be found.

Table 1. Description of study areas according to the 2009 Kenya National Demographic Census [31].

\begin{tabular}{ccccc}
\hline Study Area & Population Size & $\begin{array}{c}\text { Number of } \\
\text { Households }\end{array}$ & Area ( $\left.\mathbf{k m}^{2}\right)$ & $\begin{array}{c}\text { Population } \\
\left.\text { Density } \mathbf{( k m}^{\mathbf{2}}\right)\end{array}$ \\
\hline Kangemi Gichagi sub-location & 19,454 & 6409 & 0.87 & 22,243 \\
Ngoliba/Maguguni sub-locations & 11,636 & 3411 & 44.42 & 252 \\
\hline
\end{tabular}

Kangemi Gichagi is a densely populated urban area that can be described generally as lacking in reliable sanitation services, supply of safe water, reliable electricity and other basic services. The housing units that are prevalent in Kangemi Gichagi are common in many such densely populated low-income urban areas. They are referred to as plots. These plots contain about ten housing units under one roof, but all have private access doors. Plots share latrine and bathroom facilities as well as standpipes. A majority of the families in Kangemi Gichagi live in rented premises [31]. 
Ngoliba/Maguguni is a sparsely populated rural area with mostly semi-permanent house types. A majority of families live in private homes within their privately owned pieces of land. Houses are thus located far from each other. Only a few families that live around the shopping centers have rented premises [31]. In Ngoliba/Maguguni, latrine and bathroom facilities are privately owned and managed by the households.

\subsection{Data Acquisition and Survey Techniques}

According to Neuman [33] a quantitative approach is required for research focusing on behavior, attitudes, beliefs, opinions, characteristics, expectations and knowledge. Nevertheless, Newman [33] and Guion et al. [34] also warned of the limitation of the quantitative survey method if the data used is only about what a person says, which may differ from what he or she really does. For this study, both quantitative and qualitative survey methods were applied. In addition, own observations were also used as a means of validation. A semi-structured interview schedule as data collection instrument was used. The qualitative data were also sampled in the comment sections of the interview schedule used.

In total, 50 households in the rural Ngoliba/Maguguni study area and 49 in the urban Kangemi Gichagi study area were interviewed. Data collection was conducted during the month of November 2013. The interview schedule had six sections and addressed the following parameters: (i) the socio-demographic characteristics of the respondents; (ii) access to water-including available sources, usage, and household perceptions and preferences of the sources; (iii) drinking water safety, treatment methods and the respondents' perceptions towards these; (iv) knowledge on linkages between safe water and health; and, lastly; (v) perceptions towards the SWE. The interview process took an average of 30 minutes per respondent.

On the survey techniques, the starting point for the household survey was purposively selected to be the location of the SWE within the study areas. Households to be interviewed were then chosen at an interval of five houses, in the rural study area, and at an interval of 5 plots in the urban case. To ensure representativeness and to avoid duplication, the interviewer moved in four directions: North, South, West and East from the SWE. In Ngoliba/Maguguni, cluster sampling was applied. The first main clusters were Ngoliba sub-location and Maguguni sub-location. Ngoliba and Maguguni were further divided into sub-clusters according to the group of villages present in the area.

In each sample household, the targeted interviewee was an adult member of the family, and preferably the decision maker in issues surrounding domestic water needs. This technique was employed in order to get the relevant responses for the intended objective of this study.

\subsection{Data Analysis}

The qualitative and quantitative data collected from the field research was processed and analyzed to answer the defined research questions. Quantitative data analysis was made with IBM SPSS Statistics 22 and Microsoft Office Excel 2007, from which descriptive statistics were produced. Qualitative data was extracted by hand through identification of key words from the comments section. The qualitative data was used to interpret and find meaning behind the responses given for the corresponding quantitative data.

The Van Westendorp price-sensitivity technique was applied to analyze the willingness to pay for safe water (Figure 3) [35]. To analyze the data from the price-sensitivity model, cumulative frequency 
distributions were derived and plotted in order to specify the price perceptions. The four price lines, derived from the four questions, provide four intercept points known as the indifference price point (IPP), optimal price point (OPP), point of marginal cheapness (PMC), and point of marginal expensiveness (PME) (Figure 3). The IPP represents either the median price actually paid by consumers already in the market or the price of the product of a market leader. The OPP maximizes the number of people who would consider the offering. The Range of Acceptable Prices (RAP) is between PMC and PME and contains the vast majority of all competitive offerings in a mature market [35].

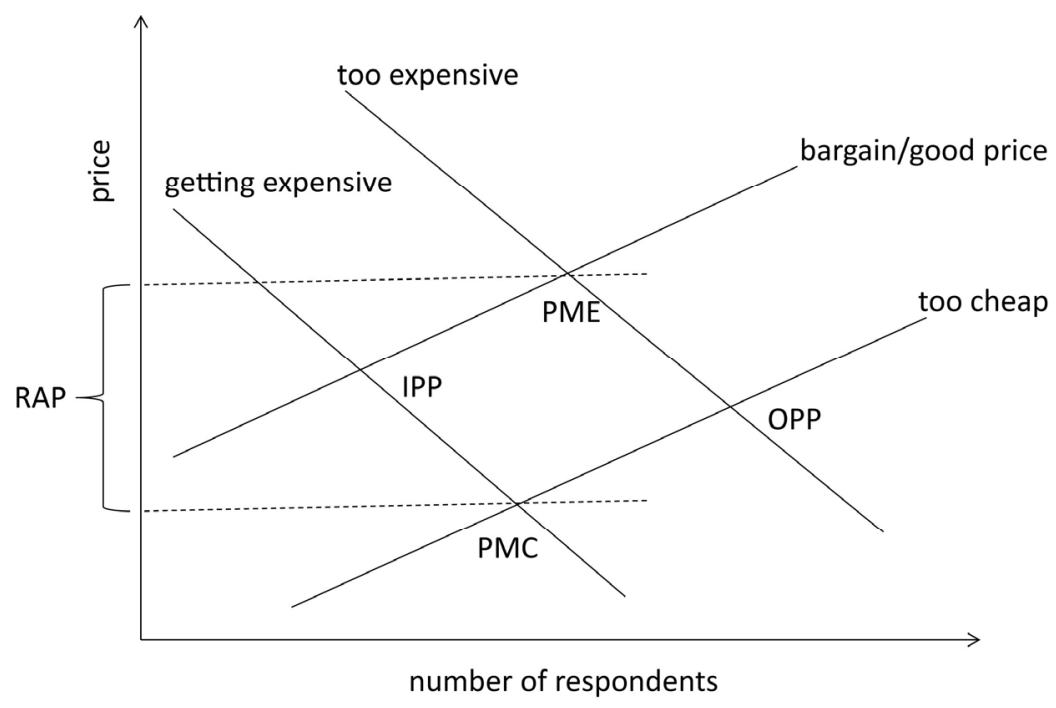

Figure 3. Range of Acceptable Prices (RAP) from the Van Westendorp price-sensitivity method (edited after Kim et al. [35]).

\section{Results}

\subsection{Demographics of Sample Households}

A total of 99 respondents were interviewed (50 in Ngoliba/Maguguni and 49 in Kangemi Gichagi). Of the interviewed respondents, $72 \%$ in Ngoliba/Maguguni and $81 \%$ in Kangemi Gichagi had acquired basic education, meaning they had completed primary school or had higher education. Female adult household members were said to make most of the decisions regarding domestic water needs, at $70 \%$ in Ngoliba/Maguguni and 77\% in Kangemi Gichagi. Eighty percent of the interviewed respondents were female. The poverty threshold for Kenya is estimated at KES 1239 (equivalent USD 15) and KES 2648 (equivalent USD 31) for rural and urban areas, respectively [36]. According to the Central Bank of Kenya, as of 31 October 2013, USD 1 = KES 85.1 [37]. From the households interviewed, 4\% of Ngoliba/Maguguni lived below the poverty line set for rural areas, while $64 \%$ lived below the poverty line set for urban areas in Kangemi Gichagi. The average household size was found to be 3.88 in Ngoliba/Maguguni and 4.08 in Kangemi Gichagi.

\subsection{Water-Service Provision of Sample Households}

The main sources of domestic water for rural Ngoliba/Maguguni and urban Kangemi Gichagi are shown in Figure 4. As it is indicated, 30\% of Ngoliba/Maguguni respondents use spring, well or 
borehole water, 24\% use water from a water kiosks, $20 \%$ use a piped connection (single tap located outside the house), $14 \%$ water vendors, $10 \%$ streams, and $2 \%$ rain water harvesting. In Kangemi Gichagi, 44\% use piped connection (38\% multi-households standpipes and $6 \%$ complete private in-house connection), 33\% use water kiosks, $15 \%$ water vendors, $6 \%$ get water from the stream, and $2 \%$ use spring, well or borehole water. When asked about their perception regarding the ideal water source imaginable, an average of $99 \%$ from both study areas found tap water in premises to be the most ideal solution. Furthermore, an average of $87 \%$ of the respondents perceived water-service provision to be a mandate of the State.

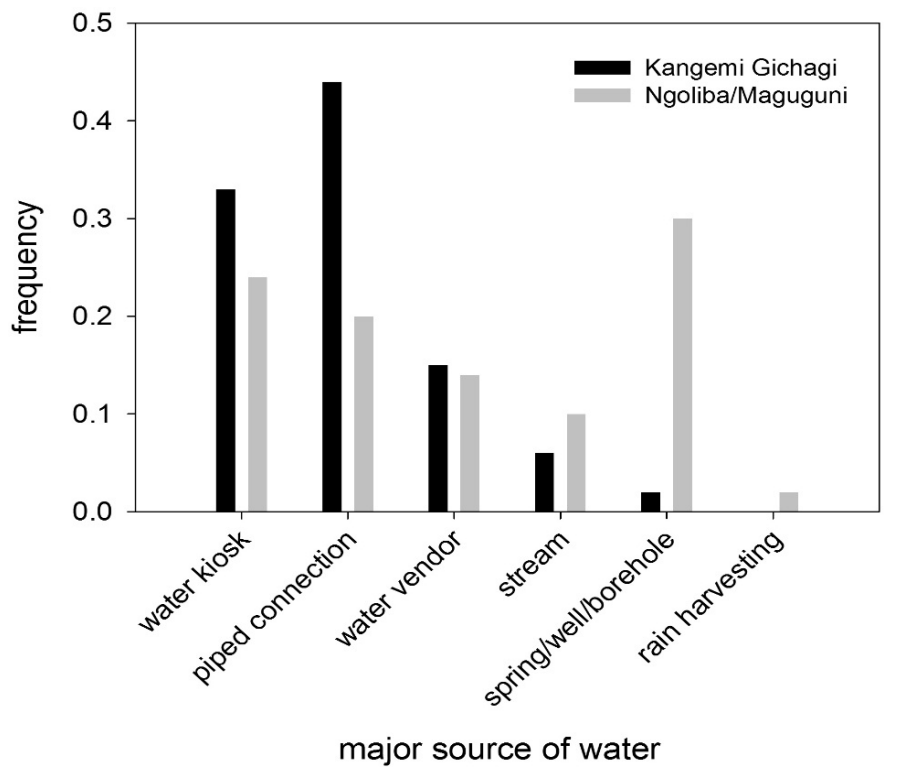

Figure 4. Main source of water in urban Kangemi Gichagi $(N=48)$, and rural Ngoliba/Maguguni $(N=50)$.

Only $14 \%$ of Ngoliba/Maguguni and 2\% of Kangemi Gichagi households regularly used one single source for domestic water. Domestic water refers to water used for washing, cooking, cleaning and drinking. In Ngoliba/Maguguni, 52\% used two sources and 33\% used three different sources of water. In Kangemi Gichagi, 35\% of respondents used two sources regularly, 53\% used three and $8 \%$ used four different sources. Respondents were further asked about the type of their sources for drinking water. In Ngoliba/Maguguni, 20\% said they retrieved their drinking water from a source different to that for other domestic activities. In Kangemi Gichagi, 40\% had a different source for drinking water. The rest of the respondents used the same water sources for both drinking and other domestic purposes.

The amount of water used by respondents was $24.40 \mathrm{~L}$ per capita per day in Ngoliba/Maguguni and 19.22 L per capita per day in Kangemi Gichagi. For drinking purposes, the average was $1.24 \mathrm{~L}$ per capita per day in Ngoliba/Maguguni and $0.84 \mathrm{~L}$ per capita per day in Kangemi Gichagi.

With regard to spending on domestic water, $56 \%$ of Ngoliba/Maguguni and 52\% of Kangemi Gichagi respondents were able to give definite amounts, which are shown in Figure 5. The reasons stated for not being able to specify the cost of the spending on water was that the respondents got their water from surface and groundwater sources, for which they did not have to pay. The second group comprised those people whose water costs were combined with the house rental bills, and where the amount of money that went to water costs was not specified to them (mostly households with standpipe water sources). 
In Ngoliba/Maguguni, 7\% of respondents paid KES 3, while 61\% paid KES 5, 3\% paid KES 10, 25\% paid KES 15, and lastly 3\% paid KES 30. In Kangemi Gichagi, 60\% paid KES 3 while 40\% paid KES 5. These are the costs for $20 \mathrm{~L}$ containers, which is the standard container widely used for purchase and storage of domestic water.

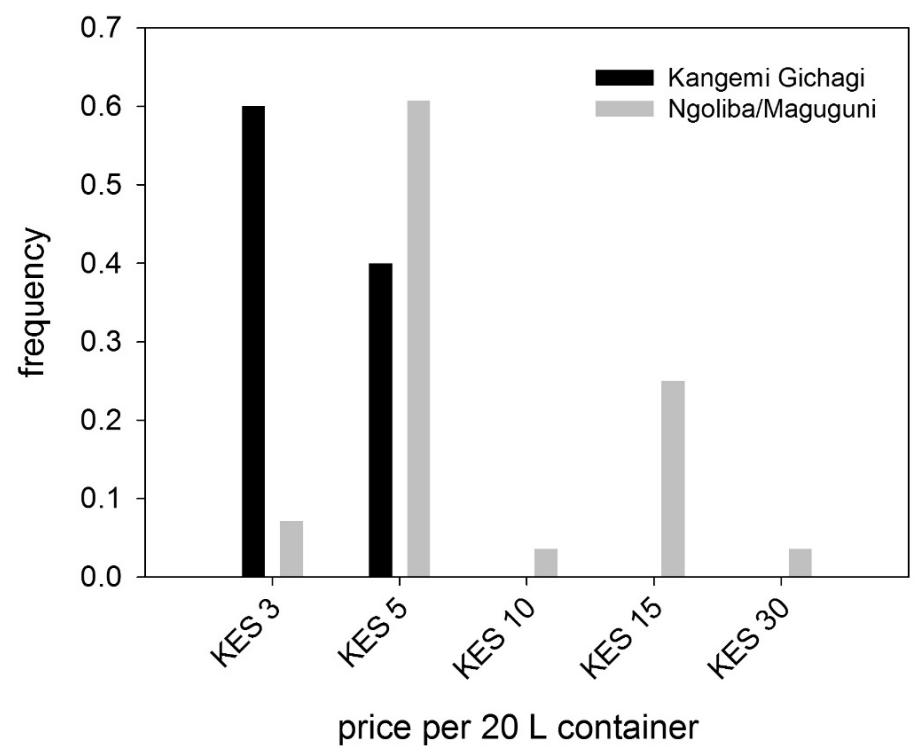

Figure 5. Household expenditure on water per 20 L container: Kangemi Gichagi (urban) $(N=25)$, and Ngoliba/Maguguni (rural) $(N=28)$ (KES $1=$ USD 0.0118).

Van Westendorp's price-sensitivity meter was applied to determine people's willingness to pay for water. The range of acceptable prices for water was found to lie between KES 5 and KES 10 for a $20 \mathrm{~L}$ container. The range between KES 2 and KES 5 was seen to be a good bargain price by 94\% of respondents (Figure 6). For this enquiry, respondents were asked about their willingness to pay for safe water from sources that are convenient to access.

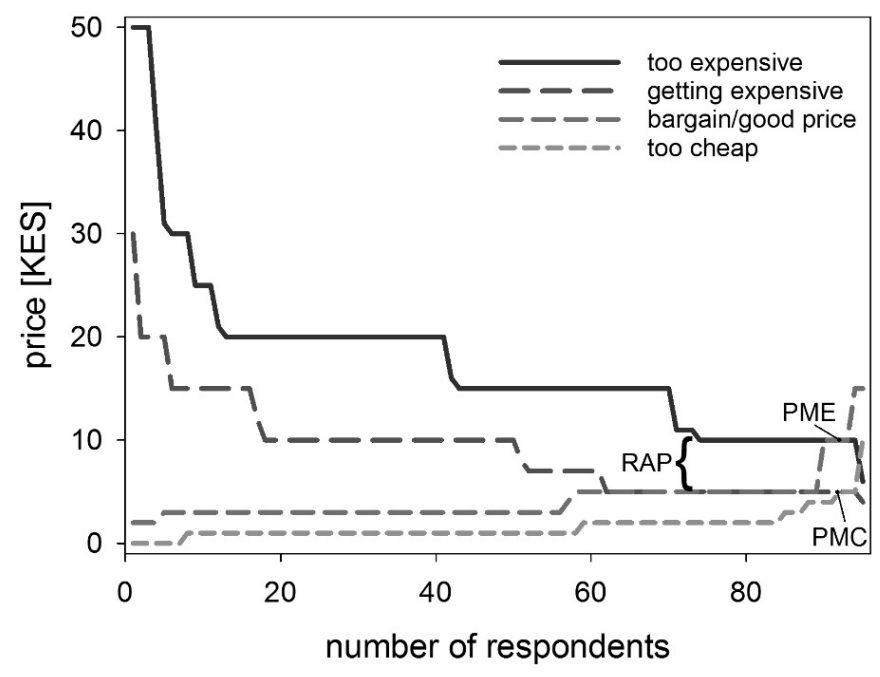

Figure 6. Range of Acceptable Price (RAP) for safe water per 20 L container in Kangemi Gichagi and Ngoliba/Maguguni, $N=96 . \mathrm{PME}=$ point of marginal expensiveness, $\mathrm{PMC}=$ point of marginal cheapness (KES $1=$ USD 0.0118). 


\subsection{Safe Water Options and Interventions of Sample Households}

Of the interviewed respondents, 16\% Ngoliba/Maguguni and 27\% Kangemi Gichagi said that they perceived their main source of water as safe to drink. Sixty percent in Ngoliba/Maguguni and 56\% in Kangemi Gichagi perceived it to be relatively safe, while $24 \%$ of Ngoliba/Maguguni and $17 \%$ Kangemi Gichagi respondents said that they perceived it to be unsafe to drink.

Sixty-nine percent of Kangemi Gichagi and $66 \%$ of Ngoliba/Maguguni respondents said that they treat their drinking water. Out of these respondents, $42 \%$ used boiling as a treatment method, $48 \%$ use chlorination and 10\% filtration in Ngoliba/Maguguni. In Kangemi Gichagi, 67\% used boiling and 33\% chlorination to treat their water. In order to investigate consistency in water treatment, respondents were asked to show if they had treated water available on the day of the interview. Only $17 \%$ of Kangemi Gichagi and $31 \%$ of Ngoliba/Maguguni respondents had treated water available. Reasons given by respondents who did not treat their water even though they had the perception that the water was unsafe or only relatively safe for drinking, were given as follows: cumbersome/difficult procedures (45\% in Ngoliba/Maguguni and 36\% in Kangemi Gichagi), lack of time (12\% in Ngoliba/Maguguni and 20\% in Kangemi Gichagi), and too costly (18\% in Ngoliba/Maguguni and 32\% in Kangemi Gichagi).

Investigations were made to find out if drinking water was kept safe during storage. Eighty-two percent of Ngoliba/Maguguni and $66 \%$ of Kangemi Gichagi respondents had their water storage facilities safely capped with a lid. 62\% in Ngoliba/Maguguni and 60\% in Kangemi Gichagi said they had a separate storage facility for drinking water from storage facility for water for other domestic uses. Eighty-eight percent of respondents in both Kangemi Gichagi and Ngoliba/Maguguni said they cleaned their water storage facilities after every refill or within a timeframe of one week.

\subsection{Link between Safe Drinking Water, Health and Hygiene}

Two questions were asked to the household respondents to find out if they had a basic understanding of the link between safe drinking water and health - in particular, diarrhea. Ninety percent of the respondents in Ngoliba/Maguguni and 94\% in Kangemi Gichagi said that they perceived diarrhea as a serious condition that can be life threatening. When asked about the causes of diarrhea, among other causes, consumption of contaminated water was mentioned by $90 \%$ of Ngoliba/Maguguni respondents and $96 \%$ of Kangemi Gichagi respondents. Additionally, on the preventive measures of diarrheal diseases, hand washing was mentioned by $100 \%$ of the respondents in both study areas. To check the probability that hand washing is practiced within the households, the respondents were asked if the household has a permanent hand washing facility. Only 16\% of Ngoliba/Maguguni and $8 \%$ of Kangemi Gichagi respondents had a permanent hand-washing station. Observation further confirmed that 33\% in Ngoliba/Maguguni and 50\% in Kangemi Gichagi of those that had permanent hand-washing stations, were not functional (did not have water) on the day of the interview. Further inquiries were made for the respondents who were without or with non-functioning hand-washing stations, in order to find out why they did not have hand-washing facilities. Sixty-nine percent of Ngoliba/Maguguni and 73\% of Kangemi Gichagi said that it was hard to maintain a hand-washing station, $19 \%$ of Ngoliba/Maguguni and 25\% of Kangemi Gichagi respondents said that lack of water was the 
problem, while $12 \%$ of Ngoliba/Maguguni and $2 \%$ of Kangemi Gichagi respondents said that they never gave it a thought or a priority.

\subsection{Perceptions toward the Safe Water Enterprises}

In both study areas, $96 \%$ of the respondents were aware of the SWE presence. Eighty-nine percent of rural Ngoliba/Maguguni and 91\% of urban Kangemi Gichagi respondents, who knew about the SWE, were also aware that the kiosk provides water that is of acceptable quality standards for drinking. While a majority of the respondents were aware of the water quality, only $24 \%$ of Ngoliba/Maguguni and $29 \%$ of Kangemi Gichagi respondents were aware of the technology applied to treat the water at the kiosk. Seventy-one percent of Ngoliba/Maguguni and 63\% of Kangemi Gichagi respondents said that whenever possible they bought water from the SWE.

With regards to the aesthetic quality, all $100 \%$ of respondents from both study areas perceived the SWE water to have aesthetic water qualities that are acceptable to them. The main reason for purchasing water from the SWE was because respondents perceive this kiosk's water to be of a superior quality, and safe, as compared to all other available sources (82\% in rural Ngoliba/Maguguni and $85 \%$ in urban Kangemi Gichagi). Sixteen percent of Ngoliba/Maguguni and 12\% of Kangemi Gichagi respondents said that proximity to their homes was the main motivation for purchasing water from the SWE kiosk.

Of the respondents who were aware of the SWE but did not purchase their water there, 92\% in Ngoliba/Maguguni and 84\% in Kangemi Gichagi gave distance from their homes as their main reason. Reliability was also given as a reason for not purchasing SWE water at $8 \%$ in Ngoliba/Maguguni and $16 \%$ in Kangemi Gichagi. On waiting time, $64 \%$ of Ngoliba/Maguguni respondents were satisfied with the waiting time to get services at the SWE. For Kangemi Gichagi, 42\% were satisfied with the waiting time. Regarding ease of accessibility, $61 \%$ of Ngoliba/Maguguni and $70 \%$ of Kangemi Gichagi said they thought the location of the SWE kiosk was suitable. As regards availability of water at the SWE kiosk, only $17 \%$ of Ngoliba/Maguguni and $40 \%$ of Kangemi Gichagi respondents said that they found the SWE kiosk reliable.

For safe drinking water, the price at the SWE Kiosk is at KES 10 for a $10 \mathrm{~L}$ container. In Ngoliba/Maguguni, 94\% of respondents said that the price was fair, and $91 \%$ of Kangemi Gichagi respondents were satisfied with the price, when the water is purposively purchased for drinking purposes.

\section{Discussion}

For the underserved households in rural and urban Kenya, the water-service options available to them can be described as a combination of many water-service providers whereby none of the service provider seemed to be dominant. The water-service providers and water sourcing options ranged from formal to informal, water suppliers to self-sourcing from ground and surface water bodies, and from regulated to non-regulated suppliers and sources. Water-service providers in the underserved areas experiment with a variety of technologies and business models. This type of water-service provision arrangement has been described as a "patchwork of utilities" [22]. As a result of significantly low connectivity to, and lack of reliability in, formal water-service providers, underserved households in rural and urban areas in Kenya tended to frequently use non-regulated water sources that were often characterized by poor water quality 
standards $[4,38]$. In the rural Ngoliba/Maguguni and the urban Kangemi Gichagi areas, it was found that the majority of households sourced their domestic water regularly from more than one source. It was also found that decisions on where to source water were made more easily, prior to water collection, in the rural study area compared to the urban. The common sources of water in the rural areas were ground or surface water sources. If present, these sources appeared to be more permanent and reliable compared to sources in highly dense urban areas where water provision involved having a supplier or a chain of suppliers. The 2009 Kenya national census reported that water-service provision in urban Kangemi Gichagi was described by residents to be erratic with up to four days a week with no water running in the taps [39]. Long waiting hours to fetch water due to low pressure were also mentioned in the report. With the erratic nature of water supply, households' decisions on where to source their water is often done spontaneously, depending on which nearest supplier has water at that point in time or on where water could be purchased within the shortest period of time. The dynamics of sourcing for water in the urban study area therefore suggested that water quality played a less significant role than convenience while making decision on where to source water. For the rural Ngoliba/Maguguni, though convenience in terms of distance to source played the major role on decisions regarding where to source domestic water, water quality concerns seemed to play a more significant role compared to the urban study area. This may be attributed to the permanent nature of water sources available. Distance was found to be the main convenience factor for the rural area, while distance and waiting time were main convenience factors for the low-income urban area.

The majority of respondents perceived water-service provision to be the mandate of the State, and in-house tap water connections as the most ideal service option. It is, however, clear that when looking at the current state of water supply in Kenya and the service demands of an ever growing population, private piped water supply cannot be guaranteed for all. Promotion of alternative solutions is therefore required.

When looking at options for safe drinking water, the respondents in both the rural and urban study areas informed that they use the same water source for both drinking and other domestic uses. These sources for drinking water were perceived to be either relatively safe or unsafe. The households reported that they were not confident on the safety of the water supplied to them by some of their regular water-service providers - such as the water kiosks and water vendors for example. They were also not confident on the safety of ground and surface water sources such as rivers, boreholes and streams. It is important to note that data and information regarding water quality tests from the formal small-scale suppliers were not available. Water quality information could not be accessed from the water points where the research was conducted. Therefore, households could also not access information regarding the quality of water they used. For informal supply and self-supply from ground and surface sources, water quality is mostly unknown. This additional information on actual water quality could have an impact on user perceptions, although the environmental conditions from these areas such as the presence of pit latrines in the rural and urban study areas and open sewers in the urban study area are indications that ground and surface water sources may most likely be contaminated. The problem of ground and surface water contamination has also been discussed in other underserved areas of Kenya [38]. For informal vendor suppliers, the source of their water is rarely traced by the households and therefore the quality of the water is questionable.

The households therefore reported that they applied household water treatment methods, with boiling and chlorination being the most commonly applied methods. However, further investigation also found 
that households did not treat their drinking water consistently. This indeed appears to be a widespread phenomenon. As many scholars have investigated and reported, the adoption and sustained use of household water safety interventions among the global poor is found to be very low [40-44]. In Ngoliba/Maguguni and Kangemi Gichagi, the three main reasons households gave for not boiling or chlorinating their drinking water were inconvenience of the processes involved, the time required and the costs of these practices. Research studies by Sobsey [44] and Peter-Varbanets et al. [13] contain in depth discussions about the influence of these determinants on the adoption and consistent use of household water treatment technologies. This current work found that many households in both the rural Ngoliba/Maguguni and urban Kangemi Gichagi were not in a position to set aside sufficient resources to cover the large amounts of energy needed to treat sufficient volumes of drinking water. Boiling of drinking water was only done to prevent the loss of energy (wood or charcoal) remaining in the fireplace after the main family meal had been prepared. This is an indication that often the complete boiling process will not be reached. Moreover, whenever there is no remaining energy biomass after cooking of the family meal, boiling of water may not be done at all.

For chlorination, the main hindrance to its consistent application in Ngoliba/Maguguni and Kangemi Gichagi was reported to be the inconsistent access to the chlorinating chemicals. Households reported that there is a possibility to access chlorinating chemicals free of charge from Community Health Workers. However, due to irregular visits by the Community Health Workers, households were not able to apply the treatment method in a consistent manner. Chlorine tablets can also be sourced from health facilities and retail shops, but this access option was not mentioned by the majority of chlorine users. Hystra [45] reported about low adoption rates of chlorine in the retail context. The report suggested that because chlorine was for a long time distributed for free by donors and NGOs, its access from other sources was not promoted. Hunter et al. [46] warns that even occasional consumption of untreated water can vitiate the impact of household water treatment. The 2009 national demographic census reported that $42 \%$ of urban households and about $60 \%$ of rural households did not treat their drinking water (Table 1) [40]. This census report (Table 1) showed that almost $50 \%$ of households in Kenya reported that they treated their drinking water.

The very low rate for treatment of drinking water in Kenya showed on the census report (Table 2) and the inconsistency in application as it has been shown by this current study are an indication for great need for alternative solutions. Providing already treated water to households could be a viable solution to the challenges discussed, of leaving the entire responsibility for water treatment to the household. In addition to water treatment, safe storage of water remains a fundamental requirement. The microbial quality of drinking water frequently declines after collection [47]. Water that is safe at the point of collection is often subject to fecal contamination during collection, transport and use in the home, mainly via unclean hands and a lack of proper cleaning of the storage containers. Such recontamination nullifies the efforts that go into treatment of the water. The WHO [47] suggests that vessels with narrow mouths and taps can significantly reduce such contamination and reduce the risk of diarrheal diseases. Consistent cleaning of storage containers and separate storage of drinking water are important.

Regarding hand washing as a measure to prevent water-borne diseases, this study found that despite the majority of the respondents reporting that they practice hand washing, there was also inconsistency in practice. Respondents explained that to clean their hands after using toilet facilities, they would ideally decant water from their main domestic storage container into another container, which they 
would use to wash their hands. This procedure can be inconveniencing to be managed on a constant basis, especially by children. Furthermore, it brings a risk of fecal contamination of the domestic water. The majority of respondents did either have no permanent hand-washing station at all or their hand-washing station was not functional on the day of the interview. The reasons given by the majority of the households interviewed for their lack of consistent hand washing practice were that it was hard to maintain the hand-washing facilities and that the lack of water also represented a challenge. This finding exposes a methodological challenge related to the dependency on self-reporting. For accuracy, it is suggested that future research about such questions should avoid self-reporting, but rather employ other techniques such as observation. This methodological challenge was also experienced with the question on how often the households cleaned their domestic water storage containers. Despite the majority of people reporting to regularly clean their containers, observations proved that only a handful of those people collecting water at the kiosks actually also cleaned their water containers. These findings further prove that the lack of consistency in safe water consumption and hygiene practices is based on practical barriers rather than on a lack of awareness and education on the link between safe water and health. Independently from the water-treatment method as such, this study suggests that a stronger focus should be laid on hygiene practices, which comprises not only education and training, but also the deployment of practical means such as hand-washing stations that can be easily maintained and sustainably managed.

Table 2. Percentage of Kenyan households by water-treatment method used according to 2009 national demographic census [41].

\begin{tabular}{cccc}
\hline Treatment Method & Urban (\%) & Rural (\%) & Total (\%) \\
\hline Boiling & 37.6 & 24.0 & 26.6 \\
Chlorination & 22.9 & 17.0 & 18.2 \\
Filtration & 1.7 & 0.6 & 0.8 \\
Solar Disinfection (SODIS) & 0.0 & 0.2 & 0.1 \\
Decantation & 0.1 & 0.4 & 0.4 \\
Other & 0.3 & 0.1 & 0.1 \\
No treatment & 42.0 & 59.7 & 56.3 \\
\hline
\end{tabular}

A comparison of rural and urban households with regards to access to safe water found no significant differences in view of the following: the water was largely perceived to be unsafe or only relatively safe in both study areas and the most common household water treatment methods were boiling and chlorination. Challenges to the application of the household treatment methods were faced in both study areas. Regarding hygiene practices, however, it was found that the urban households used shared facilities while in the rural area the majority of households used private facilities. Communal management of the hand-washing facilities was therefore found to be a challenge for consistency in hand-washing practices that is rather unique to the urban area. Tumwebaze [48] has contributed to research focusing on social dilemma factors regarding collective cleaning behavior of shared toilet users in some African countries - an area of research that has a great impact on the consistency of hygiene practices in urban informal settlements in developing countries.

The prices for water in low-income rural and urban underserved areas have been understood to always be much higher than in higher-income areas that are connected to household tap water. Hystra [49] reported from slums of Jakarta and rural Cambodia that despite being under-serviced, the people at the base of the 
pyramid generally paid more for water compared to people at the top of that pyramid. The range of acceptable prices for safe water and the prices at water kiosks in rural Ngoliba/Maguguni and urban Kangemi Gichagi were found to be generally higher than the tariff, set by the Water Services Regulatory Board (WSRB), for water kiosks in the specific regions. What is more, some households also paid extra charges to have the water delivered to their homes by water vendors. This indicated that in order to save time and to compensate the burden of fetching water, households were willing to pay higher prices for the services. In their argument supporting market-driven approach for sanitation services in East Africa's urban slums, O'Keefe et al. [30] have mentioned one of their reasons for it to be the recognition that people already paid for sanitation services and that the "market" could be entered with improved products and services in order to generate mutual benefit for users and providers of the system. This argument could also support improvement of drinking water services for underserved areas with innovative safe drinking water provision models.

With regards to the perception towards the SWE, there was a high level of trust in the quality of the water. This was despite the fact that only very few of the respondents were aware of the water treatment processes employed at the SWE kiosks. Professionalism in service provision, compared to other kiosk sources, was given as a reason of high levels of trust by clients of the SWEs. Respondents said that they appreciated the professionally designed kiosks and the branded containers, clean and hygienic surroundings, good service and emphasis on health shown by the information materials, in form of posters and leaflets, available at the SWE kiosk. This response was in comparison with other available water providers within their reach, in which the majority of the respondents had a low level trust regarding the quality of their water.

Comparing the perceptions of the two commonly used household water treatment methods (boiling and chlorination) and the purchase of purified water from the SWE, the households showed a greater preference for the SWE. The main reasons given included that it enabled users to circumvent the inconvenient tasks of applying household treatment methods and thereby saving time. Another important reason seemed to be the perceived sense of an elevated image of the SWE users in their society.

The better perception and preference for the SWE were also reflected in people's willingness to pay even higher prices. The majority of respondents from both the rural and urban study areas perceived the price of water at SWE kiosk to be fair, even when the price was two times higher than the normal price range for domestic water in the area. This was for the water to be purchased as safe drinking water and not for other domestic uses. This finding supports empirical research by Hystra [45], who found that even low-income households based their purchase decision rather on the valuation of the product than on its price. In his report for the World Bank, McLean [50] found that evidence from new decentralized approaches confirmed that users were willing to pay for water services that are tailored to their needs, this being true across all income levels. Willingness to pay for the services is very relevant for the financial sustainability of decentralized small-scale kiosk concepts. Financial sustainability is possible if the systems are designed such that they provide both the capability as well as the right incentives to identify and respond to consumers' needs. The finding that some households buy SWE water because it elevates their image in society validates experiences from the Safe Water Network and the Safe Water Enterprises, which suggest that Base-of-the-Pyramid consumers do not always want to buy a product that has been designed for the poor [51,52]. Having a good image within a community is a social aspect that is also highly valued by low-income households. It can be regarded as part of the human dignity of 
all people, no matter whether they have a low- or high-income background. From observations of the households that perceived purchasing SWE water elevated their image in society, it was clear that using a nice and clean water container was also an appealing factor, as it was perceived to be almost comparable to products from the bottled water industry. The bottled water industry has strongly penetrated the water market in developing countries, so that bottled water was usually found to have a better image compared to other sources and packaging for drinking water. Weyrich and Butler [52] suggested that marketing strategies of the bottled water market might be an interesting point of reference when looking at ways to stimulate water provision and services of decentralized kiosks, which, moreover, serve water at a lower price and save on wastage by using reusable containers.

Decentralized models for water-service provision such as the SWE for example have generally been perceived as temporary and second-best solutions next to private piped household connections. This study, however, highlights its significance to possibly increase consistency, in the long-term, for safe water consumption in the context of low-income underserved households. Furthermore, when looking at the current state of water supply in Kenya and the service demands of an ever growing population, it is clear that household piped water supply cannot be guaranteed for all. The World Bank [53] for instance has reported that due to urbanization trends in Kenya, access to piped water or public tap water for towns and cities adjacent to the city of Nairobi declined by over two percent per year between 1989 and 2009. This trend is likely to accelerate. This study realized the need to promote such decentralized approaches as long-term solutions. The scientific community has also in large based their discussions around decentralized models as temporary solutions. Sima et al. [26] described how decentralized drinking water refill stations may act as a short-term alternative to existing approaches. The World Bank [53] also reported that their earlier decentralized projects were designed as temporary and emergency intervention solutions. More research is therefore called for that focuses on the application of decentralized water-service provision solutions as long-term solutions. Such research interventions should also target the change of perceptions by consumers because it is in fact unlikely that centralized water systems would actually expand in the foreseeable future.

\section{Conclusions}

Underserved rural and urban households access domestic water from an array of water-service providers, the so-called "patchwork of utilities", whose water quality standards vary and are mostly unknown. As a result of this empirical case study focusing on the SWE concept, it is suggested that a decentralized concept can offer a viable alternative for safe drinking water to underserved low-income consumers, considering the following criteria: end-of-pipe treatment application, low-cost and reliable treatment technology, and an entrepreneurial management setup. The current state of centralized water supply system in Kenya cannot guarantee piped water connections to significantly cover all households. Decentralized approaches therefore ought to be promoted. The SWE concept has proved to be the preferred option among the water-service provision options that are available in Ngoliba/Maguguni and Kangemi Gichagi.

This study found that consistency in applying household water treatment methods have been hindered by the fact that great responsibility is given to households who lack the time and resources to apply those methods on a daily basis. A decentralized water kiosk concept can solve these challenges through 
end-of-pipe water treatment whereby the only responsibility left to households is safe storage. Purchasing already purified water is perceived to be a convenient solution and one that is capable of enabling a consistent consumption of safe water by underserved rural and urban households. This was further supported by people's willingness to pay higher prices for SWE drinking water.

Decentralized solutions for water quality improvement and access to safe water are growing both in numbers and reach. In this context, it is of crucial importance to understand user perceptions and preferences, as this will ensure that these solutions can be set up in a sustainable way for the benefit of communities and human welfare. In addition, this development however also calls for a holistic study that looks into the economical, managerial and environmental perspectives, which will enable better understanding of the long-term sustainability impacts of such decentralized solutions within the larger context of water supply.

\section{Acknowledgments}

We would like to thank Caroline Weimann for editing the language of our manuscript and the anonymous reviewers for insightful comments and suggestions that helped to improve the quality of the manuscript. This work was supported by the German Research Foundation (DFG) and the Technische Universität München within the funding program Open Access Publishing, and by Siemens Stiftung. The study was further supported by the Technische Universität München-Institute for Advanced Study, funded by the German Excellence Initiative.

\section{Author Contributions}

Pauline Chepchirchir Cherunya and Christine Janezic conceived of and designed the overall concept and work plan for the research. Pauline Chepchirchir Cherunya and Michael Leuchner developed the research methodology. Pauline Chepchirchir Cherunya conducted the data collection and analyzed the data under the supervision of Michael Leuchner and Christine Janezic. Editing of the paper was conducted together by the three authors.

\section{Conflicts of Interest}

The authors declare no conflict of interest.

\section{References}

1. Koundouri, P.; Pashardes, P.; Swanson, T.; Xepapadeas, A. The Economics of Water Management in Developing Countries: Problems, Principles and Policies; Munich Personal RePEc Archive: Munich, Germany, 2003.

2. Prüss-Üstün, A.; Bos, R.; Gore, F.; Bartram, J. Safer Water, Better Health: Costs, Benefits and Sustainability of Interventions to Protect and Promote Health; World Health Organization: Geneva, Switzerland, 2008.

3. Hutton, G. Unsafe water and lack of sanitation. In Solutions for the World's Biggest Problems: Costs and Benefits; Lomborg, B., Ed.; Cambridge University Press: Cambridge, UK, 2007; pp. $405-424$. 
4. World Bank. Citizen's Report Card on Urban Water, Sanitation and Solid Waste Services in Kenya: Summary of Results from Nairobi; World Bank: Washington, DC, USA, 2008.

5. Water Services Regulatory Board (WSRB). Impact: A Performance Review of Kenya's Water Services Sector 2011-2012; Water Services Regulatory Board: Nairobi, Kenya, 2013.

6. Danida. Lessons Learned and Good Practices from Support to the Kenyan Water Sector; Royal Danish Embassy; Danida: Nairobi, Kenya, 2010.

7. Ali, S. Alternatives for safe water provision in urban and peri-urban slums. J. Water Health 2010, 8, 720-734.

8. United Nations Human Settlements Programme (UN-Habitat). The Challenge of Slums: Global Report on Human Settlements 2003; UN-Habitat: London, UK; Sterling, VA, USA, 2004; pp. 337-338.

9. Siakilo, E. Characteristics and the state of land ownership in informal settlements in Nairobi, kenya. Int. J. Innov. Sci. Res. 2014, 3, 218-226.

10. Werchota, R. The Growing Urban Crisis in Africa: Water Supply, Sanitation and Demographic Challenges-the Kenyan Case; Deutsche Gesellschaft fuer Internationale Zusammenarbeit (GIZ) GmbH: Eschborn, Germany, 2013.

11. Government of Kenya. The Draft National Water Policy; Ministry of Water and Irrigation: Nairobi, Kenya, 2012.

12. Opryszko, M.; Huang, H.; Soderlund, K.; Schwab, K. Data gaps in evidence-based research on small water enterprises in developing countries. J. Water Health 2009, 7, 609-622.

13. Peter-Varbanets, M.; Zurbrügg, C.; Swartz, C.; Pronk, W. Decentralized systems for potable water and the potential of membrane technology. Water Res. 2009, 43, 245-265.

14. Golooba-Mutebi, F. In search of the right formula: Public, private and community-driven provision of safe water in Rwanda and Uganda. Public Adm. Dev. 2012, 32, 430-443.

15. Cohen, J.M.; Peterson, S.B. Administrative Decentralization: A New Framework for Improved Governance, Accountability, and Performance; Harvard Institute for International Development, Harvard University: Cambridge, MA, USA, 1997; Volume 582.

16. United Nations Development Programme (UNDP). Decentralisation: A Sampling of Definitions; UNDP: New York, NY, USA, 1999.

17. Masanyiwa, Z.S.; Niehof, A.; Termeer, C. Institutional arrangements for decentralized water and health services delivery in rural Tanzania: Differences and constraints. Basic Res. J. Soc. Polit. Sci. 2013, $1,77-88$.

18. Steiner, S. Decentralisation and Poverty Reduction: A Conceptual Framework for the Economic Impact; German Overseas Institute (DÜI): Hamburg, Germany, 2005.

19. Ekpo, A. Decentralization and Service Delivery: A Framework; African Economic Research Consortium: Nairobi, Kenya, 2008.

20. Decentralization Thematic Team. What is Decentralization? Colombia University Center for International Earth Science Information Network (CIESIN): Palisades, NY, USA, 2001.

21. Kariuki, M.; Schwartz, J. Small-Scale Private Service Providers of Water Supply and Electricity: A Review of Incidence, Structure, Pricing, and Operating Characteristics; World Bank Publications: Washington, DC, USA, 2005; Volume 3727. 
22. Peloso, M.; Morinville, C. The "daily chase" for water in Ashaiman, Ghana: Making space for agency and water users in the urban informal water network. Water Altern. 2014, 7, 121-139.

23. Safe Water Network; International Finance Corporation. The Decentralized Water Market-Assessing and Overcoming the Hurdles to Scale in Kenya; International Finance Corporation and Safe Water Network: Nairobi, Kenya, 2013.

24. Sara, J.; Katz, T. Making the Rural Water Supply Sustainable: Report on the Impact of Project Rules; UNDP/World Bank Water and Sanitation Program: Washington, DC, USA, 1997.

25. Siemens Stifrung. Safe Water Enterprises. Available online: https://www.siemens-stiftung.org/en/ projects/safe-water-enterprises (accessed on 1 April 2015).

26. Sima, L.C.; Elimelech, M. More than a drop in the bucket: Decentralized membrane-based drinking water refill stations in Southeast Asia. Environ. Sci. Technol. 2013, 47, 7580-7588.

27. SkyJuice Foundation. Skyhydrant ${ }^{\circledR}$ Water Filtration Unit. Available online: http://www.skyjuice.com.au/documents/SKYHYDRANTINSTRUCTIONS.pdf (accessed on 17 April 2015).

28. Butler, R. Skyjuice technology impact on the UN-MDG outcomes for safe affordable potable water. Desalination 2009, 248, 622-628.

29. World Health Organization (WHO). A Toolkit for Monitoring and Evaluating Household Water Treatment and Safe Storage Programmes; WHO: Geneva, Switzerland, 2012.

30. O’Keefe, M.; Lüthi, C.; Tumwebaze I.K.; Tobias, R. Opportunities and limits to market-driven sanitation services: Evidence from urban informal settlements in East Africa. Environ. Urban. 2015, doi:10.1177/0956247815581758.

31. Kenya Online Database Initiative. Census Volume 1 Question 1 Population, Households and Density by Sublocations -2009 08.07.2011 ed.; Kenya National Bureau of Statistics: Nairobi, Kenya, 2015.

32. Dalet, D. Map of the Republic of Kenya with County Boundaries. Le Logis-Neuf: Marcoux. Available online: http://d-maps.com/carte.php?num_car=237\&lang=en (accessed on 17 April 2015).

33. Neuman, W.L. Social Research Methods: Qualitative and Quantitative Approaches; Pearson Education: Boston, MS, USA, 2006.

34. Guion, L.A.; Diehl, D.C.; McDonald, D. Triangulation: Establishing the Validity of Qualitative Studies; University of Florida: Gainesville, FL, USA, 2011.

35. Kim, H.; House, L.A.; Gao, Z. Theoretical and perceptual market values for fresh squeezed orange juice. Int. J. Mark. Stud. 2012, 4, doi:10.5539/ijms.v4n2p45.

36. KNBS. Basic Report on Well-Being in Kenya. Based on Kenya Integrated Household Budget Survey 2005/06; Kenya National Bureau of Statistics: Nairobi, Kenya, 2007.

37. Central Bank of Kenya. Foreign Currency Exchange. Available online: https://www.centralbank. go.ke/index.php/rate-and-statistics/exchange-rates-2?yr=2013\&mn=10 (accessed on 17 April 2015).

38. Kimani-Murage, E.W.; Ngindu, A.M. Quality of water the slum dwellers use: The case of a Kenyan slum. J. Urban Health Bull. N. Y. Acad. Med. 2007, 84, 829-838.

39. Kenya Online Database Initiative. Housheold Access to Water by Sublocation-2009. 08.07.2011 ed.; Kenya National Bureau of Statistics: Nairobi, Kenya, 2015.

40. Turrini, G. Perceptions of Safety and Household Behaviors to Improve Drinking Water Quality in Peri-Urban Cambodia; Duke University: Durham, NC, USA, 2013. 
41. Fumbi, C.J. End User Perception and Willingness-to-Pay for Gravity Driven Membrane Disinfection in Nakuru-Kenya; Unesco-IHE: Delft, the Netherlands, 2012.

42. Luoto, J.; Levine, D.; Albert, J. Information and Persuasion: Achieving safe water behaviors in Kenya; RAND Working Paper Series No. WR-885; Social Science Research Network (SSRN): Rochester, NY, USA, 2011.

43. Figueroa, M.E.; Kincaid, D.L. Social, Cultural and Behavioral Correlates of Household Water Treatment and Storage; World Health Organisation: Geneva, Switzerland, 2007.

44. Sobsey, M.D.; Stauber, C.E.; Casanova, L.M.; Brown, J.M.; Elliott, M.A. Point of use household drinking water filtration: A practical, effective solution for providing sustained access to safe drinking water in the developing world. Environ. Sci. Technol. 2008, 42, 4261-4267.

45. Hystra. Access to Safe Water for the Base Of the Pyramid: Lessons Learned from 15 Case Studies; Hystra Report: Paris, France, 2011.

46. Hunter, P.; Zmirou-Navier, D.; Hartemann, P. Estimating the impact on health of poor reliability of drinking water interventions in developing countries. Sci. Total Environ. 2009, 407, 2621-2624.

47. WHO. Combating Waterborne Disease at the Household Level; World Health Organization; International Network to Promote Household Water Treatment and Safe Storage: Geneva, Switzerland, 2007.

48. Tumwebaze, I.K.; Mosler, H.J. Dirty Toilets a Health Threat: Social-Cognitive and Dilemma Factors Influencing Collective Cleaning of Shared Toilets in Kampala's Urban Slums, Uganda. In 28th Conference of the European Health Psychology Society; European Health Psychology Society: Innsbruck, Austria, 2014.

49. Hystra. Marketing Innovative Devices for the Base of the Pyramid; Hystra Report: Paris, France, 2013.

50. McLean, K. Decentralization of Water Supply. In Decentralization Briefing Notes; World Bank Institute: Washington, DC, USA, 2002; pp. 72-76.

51. Safe Water Network. Unlocking Consumer Demand for Water: A Collaborative Project; World Water Week, Stockholm, 4.09.2013, 2013 [side event presentation]; Stockholm International Water Institute: Stockholm, Sweden, 2013.

52. Weyrich, C.; Butler, R. Experiences and analysis of safe water kiosk models in Kenya. In International Water Association (IWA) Development Congress and Exhibition; International Water Association: Nairobi, Kenya, 2013.

53. World Bank. Kenya Economic Report. Time to Shift Gears-Accelerating Growth and Poverty Reduction in the New Kenya. No. 8, June 2013; Poverty Reduction and Economic Management Unit Africa Region: Nairobi, Kenya, 2013.

(C) 2015 by the authors; licensee MDPI, Basel, Switzerland. This article is an open access article distributed under the terms and conditions of the Creative Commons Attribution License (http://creativecommons.org/licenses/by/4.0/). 